\title{
Quantum Mechanistic Studies of the Oxidation of Ethylene by Rhenium Oxo Complexes
}

\author{
Emmanuel Adu Fosu, ${ }^{1}$ Collins Obuah $\mathbb{D}^{1},{ }^{1}$ Louis Hamenu, ${ }^{1}$ Albert Aniagyei ${ }^{D},{ }^{2}$ \\ Michael Kojo Ainooson, ${ }^{1}$ and Krishna K. Govender $\mathbb{D D}^{3,4}$ \\ ${ }^{1}$ Department of Chemistry, University of Ghana, Legon, Accra, Ghana \\ ${ }^{2}$ School of Basic and Biomedical Sciences, University of Health and Allied Sciences, Ho, Ghana \\ ${ }^{3}$ Department of Chemical Sciences, University of Johannesburg, P. O. Box 17011, Doornfontein Campus, \\ Johannesburg 2028, South Africa \\ ${ }^{4}$ Council for Scientific and Industrial Research, National Integrated Cyber Infrastructure, \\ Centre for High Performance Computing, 15 Lower Hope Road, Rosebank, Cape Town 7700, South Africa
}

Correspondence should be addressed to Collins Obuah; cobuah@ug.edu.gh

Received 11 May 2021; Revised 28 July 2021; Accepted 10 August 2021; Published 23 August 2021

Academic Editor: Marcelino Maneiro

\begin{abstract}
Copyright (c) 2021 Emmanuel Adu Fosu et al. This is an open access article distributed under the Creative Commons Attribution License, which permits unrestricted use, distribution, and reproduction in any medium, provided the original work is properly cited.
\end{abstract}

\begin{abstract}
Transition-metal-mediated oxygen transfer reactions are of importance in both industry and academia; thus, a series of rhenium oxo complexes of the type $\mathrm{ReO}_{3} \mathrm{~L}\left(\mathrm{~L}=\mathrm{O}^{-}, \mathrm{Cl}^{-}, \mathrm{F}^{-}, \mathrm{OH}^{-}, \mathrm{Br}^{-}, \mathrm{I}^{-}\right)$and their effects as oxidation catalysts on ethylene have been studied. The activation and reaction energies for the addition pathways involving multiple spin states (singlet and triplet) have been computed. In all cases, structures on the singlet potential energy surfaces showed higher stability compared to their counterparts on the triplet potential energy surfaces (PESs). Frontier Molecular Orbital calculations show electrons flow from the $\mathrm{HOMO}$ of ethylene to the LUMO of rhenium for all complexes studied except $\mathrm{ReO}_{4}{ }^{-}$where the reverse case occurs. In the reaction between $\mathrm{ReO}_{3} \mathrm{~L}\left(\mathrm{~L}=\mathrm{O}^{-}, \mathrm{Cl}^{-}, \mathrm{F}^{-}, \mathrm{OH}^{-}, \mathrm{Br}^{-}\right.$, and $\left.\mathrm{I}^{-}\right)$and ethylene, the concerted [3+2] addition pathway on the singlet $\mathrm{PES}$ leading to the formation of dioxylate intermediate is favored over the [2+2] addition pathway leading to the formation of a metallaoxetane intermediate and subsequent rearrangement to the dioxylate. The activation and the reaction energies for the formation of the dioxylate on the singlet PES for the ligands studied followed the order $\mathrm{O}^{-}>\mathrm{OH}^{-}>\mathrm{I}^{-}>\mathrm{F}^{-}>\mathrm{Br}^{-}>\mathrm{Cl}^{-}$and $\mathrm{O}^{-}>\mathrm{OH}^{-}>\mathrm{F}^{-}>\mathrm{I}^{-}>\mathrm{Br}^{-}>\mathrm{Cl}^{-}$, respectively. Furthermore, the activation and the reaction energies for the formation of the metallaoxetane intermediate increase in the order $\mathrm{O}^{-}>\mathrm{OH}^{-}>\mathrm{I}^{-}>\mathrm{Br}^{-}>\mathrm{Cl}^{-}>\mathrm{F}^{-}$and $\mathrm{O}^{-}>\mathrm{Br}^{-}>\mathrm{I}^{-}>\mathrm{Cl}^{-}>\mathrm{OH}^{-}>\mathrm{F}^{-}$, respectively. The subsequent rearrangement of the metallaoxetane intermediate to the dioxylate is only feasible in the case of $\mathrm{ReO}_{4}{ }^{-}$. Of all the complexes studied, the best dioxylating catalyst is $\mathrm{ReO}_{3} \mathrm{Cl}$ (singlet surface) and the best epoxidation catalyst is $\mathrm{ReO}_{3} \mathrm{~F}$ (singlet surface).
\end{abstract}

\section{Introduction}

One of the primary goals in chemical research is to develop novel catalytic reactions that increase the selectivity and efficiency of chemical processes [1,2]. Exploring chemical systems at the fundamentals of matter has led to the rational formulation and understanding of novel chemical catalytic processes or reactions, understanding transient properties, and identification of key intermediates due to the uncontrollable nature of chemical reactions or processes [3]. In the industrial and academic field, organometallic-mediated oxygen transfer processes, or reactions, have shown great relevance over the past years [3]. The catalytic oxidation of olefinic bonds to form vicinal diols by the osmium tetroxide catalyst is a typical and well-known example of oxygen transfer processes or reactions $[4,5]$.

The osmium tetroxide catalytic oxidation of prochiral olefinic substrates together with asymmetric amine ligands as chiral auxiliaries shows a very high enantioface selectivity [6]. Experimental and theoretical works over the past year 
have shown the stability of epoxide formation via the catalyzed oxidation pathways by early transition metals such titanium, vanadium, and chromium [7-9] whereas oxo complexes such as ruthenium tetroxide [9], osmium tetroxide [4], and permanganate [10] tend to prefer cisdihydroxylate olefinic substrates [11]. Exploring and understanding the mechanistic channels of olefinic catalyzed substrates, especially osmium tetroxide, has been a subject of interest and study due to the relevance of their cis-dihydroxylate and epoxide products.

Early suggestions about the catalytic oxidation of the ethylene by $\mathrm{OsO}_{4}$ complex was that the addition mechanistic pathway is energetically favorable for the formation of dioxylate via a $[3+2]$ insertion of the $\mathrm{O}=\mathrm{Os}=\mathrm{O}$ moiety across the olefinic bond which forms a dioxylate intermediate which has been experimentally characterized with its hydrolysis forming diols [6]. However, Sharpless et al. [9] raised arguments about the $[3+2]$ mechanistic route and made a case for the $[2+2]$ pathway due to the primary products (dichlorides, epoxides, and chlorohydrins) from the chromyl chloride catalyzed oxidation of olefins. A new proposal was then made by Sharpless et al. [9] where they suggested that the oxidative mechanism was via a $[2+2]$ addition route or stepwise mechanism which results in metallaoxetane intermediate before rearranging through another transient to form a dioxylate complex. Arguments on the mechanistic details of the osmium tetroxide catalytic oxidation of olefins, however, have been settled after improved quantum simulations over the past years predicted both kinetic and thermodynamic stability via the $[3+2]$ pathway over the $[2+2]$ pathway $[1,5,6,12-15]$. Osmium tetroxide has been one of the best catalysts for most oxygen transfer reactions, but due to its volatility, toxicity, scarcity, and expensive nature, these factors demerit the use of osmium tetroxide as a catalyst and urge researchers to investigate alternative metal oxo complexes or substrate catalysts to replace osmium tetroxide.

Rhenium is next to osmium on the periodic table. Catalytic oxidation of olefinic substrates by $\mathrm{ReO}_{3} \mathrm{~L}$ oxo complexes has mainly been focused on the $[3+2]$ and $[2+2]$ addition pathway $[11,13,14,16]$ using different levels of theory with only Aniagyei et al. [16] investigating an epoxide formation plausibility. However, Herrmann et al. [13] reported rhenium oxo complexes are good oxygen-transfer catalysts $[13,17]$.

Using a hybrid DFT model, B3LYP [18], and the Hay-Wadt relativistic effective core potential (ECP) for Re (LANL2) and a double zeta basis set, 6-31G*, for other atoms, Pietsch et al. [11] studied the [3+2] and [2+2] mechanistic pathways by aiming at the thermodynamic properties for the ethylene-catalyzed oxidation by $\mathrm{ReO}_{3} \mathrm{~L}$ complexes $\left(\mathrm{L}=\mathrm{Cp}^{*}, \mathrm{Cp}, \mathrm{Cl}, \mathrm{CH}_{3},{ }^{-} \mathrm{OH},{ }^{-} \mathrm{OCH}_{3}\right.$, and $\left.\mathrm{O}^{-}\right)$. Pietsch et al. [11] used qualitative molecular orbital diagrams and concluded that the $\pi$-donor strength of the ligands (L) accounts for the reactivity differences of this type of complex [16].

Deubel and Frenking [19] continued the theoretical works by Pietsch et al. [11] and verified these claims by reporting the calculated PES for the $[3+2]$ and $[2+2]$ insertion of the $\mathrm{ReO}_{3} \mathrm{~L}$ oxo complex $\left(\mathrm{L}=\mathrm{O}^{-}, \mathrm{Cl}\right.$, and $\mathrm{Cp}$ ) across the olefinic bond and the interconversion of the oxetane intermediate to its dioxylate, at the B3LYP [18] level using relativistic small-core ECPs with a valence basis set splitting (441/2111/21) for Re and 6-31G(d) all-electron basis sets for all other atoms. Findings from the theoretical simulations by Deubel and Frenking [19] showed stability for the $[3+2]$ mechanistic pathway over the $[2+2]$ pathway. The $[3+2]$ pathway was found to be lower in energies relative to that of the rearrangement of the oxetane intermediate to a dioxylate intermediate. By employing knowledge from frontier orbital and charge transfer models, Deubel and Frenking [19] rationalized the reactivity differences of the complexes.

Gisdakis and Rösch [20], in auxiliary to the computations performed by Pietsch et al. [11] and Deubel and Frenking [19], assigned charges $(q=-1,0,1)$ to the $\mathrm{ReO}_{3} \mathrm{~L}$ molecule such that the molecular systems are isoelectronic to $\mathrm{OsO}_{4}$. They explored the mechanism of the $[3+2]$ cycloaddition of $\mathrm{ReO}_{3} \mathrm{~L}\left(\mathrm{~L}=\mathrm{O}^{-}, \mathrm{CH}_{3}, \mathrm{Cl}\right.$, and $\left.\mathrm{Cp}\right)$ to ethylene using the hybrid DFT model B3LYP, with (ECP) effective core potentials and double-zeta basis sets, LANL2DZ, for the Re atom and 6-311G (d, p) basis sets for other atoms. Gisdakis and Rösch [20] did not study the formation of the dioxylate intermediates from the metallaoxetane along the $[2+2]$ addition pathway.

Aniagyei et al. [16] furthered the theoretical works by Pietsch et al. [11], Deubel and Frenking [19], and Gisdakis and Rösch [20] by using a hybrid density functional theory at the B3LYP [18]/LACVP* level of theory to study the concerted and stepwise addition pathways for the oxidation of ethylene by $\mathrm{ReO}_{3} \mathrm{~L}\left(\mathrm{~L}=\mathrm{O}^{-}, \mathrm{Cl}^{-}, \mathrm{Cp}, \mathrm{CH}_{3},{ }^{-} \mathrm{OCH}_{3}\right.$, and $\mathrm{NPH}_{3}$ ) on several spin PES (spin multiplicity = 1, 2, 3, and 4, where applicable).

Aniagyei et al. [16] concluded that the catalytic oxidation of ethylene by the $\mathrm{ReO}_{3} \mathrm{~L}$ complex $\left(\mathrm{L}=\mathrm{OCH}_{3}, \mathrm{O}^{-}, \mathrm{CH}_{3}\right.$, $\mathrm{NPH}_{3} \mathrm{Cl}^{-}$, and $\mathrm{Cp}$ ) shows both kinetic and thermodynamic favorability on the $[3+2]$ pathway leading to the formation of a metallacycle over the $[2+2]$ mechanistic pathway which forms an oxetane intermediate before rearranging into a dioxylate intermediate on the singlet PES. The rearrangement of the oxetane intermediate into the dioxylate intermediate was kinetically hindered except for the reaction between ethylene and the perrhenate ion on the singlet PES. The formation of an epoxide precursor was plausible in the case of $\mathrm{ReO}_{3} \mathrm{~L}\left(\mathrm{~L}=\mathrm{Cl}^{-}, \mathrm{CH}_{3},{ }^{-} \mathrm{OCH}_{3}, \mathrm{NPH}_{3}\right)$ reaction with ethylene although these reaction modes showed endergonicity in all cases on the singlet PES [16].

This work reports on the extended works by Aniagyei et al. [16], Pietsch et al. [11], Deubel and Frenking [19], and Gisdakis and Rösch [20] by employing a hybrid DFT model, B3LYP, at the B3LYP [18]/LACVP* level of theory to investigate all the concerted mechanistic channels. This report also confirms results by Aniagyei et al. on $\mathrm{ReO}_{4}{ }^{-}$and $\mathrm{ReO}_{3} \mathrm{Cl}$ as well as a new derivative of $\mathrm{ReO}_{3} \mathrm{~L}\left(\mathrm{~L}=\mathrm{F}^{-}, \mathrm{Br}^{-}, \mathrm{I}^{-}\right.$, and $\mathrm{OH}^{-}$). Multiple spin states (singlet and triplet) have also been considered in the calculations due to the nature of organometallic reactions which tend to show spin multiplicity flips on the PES. Furthermore, a change of spin 
multiplicity affects the molecular geometry and spin multiplicity crossing effects can dramatically affect reaction mechanisms of organometallic transformations [21, 22].

\section{Computational Details}

The density functional/Hartree-Fock hybrid [23-25] model B3LYP [18] as implemented in Spartan'16 V.2.0.7 [26] has been used throughout this study together with the basis set of LANL2DZ for rhenium and iodine atoms and the split valence double- $\xi$ (DZ) [27] 6-31G (d) for the other nonmetal atoms $\left(\mathrm{O}^{-}, \mathrm{Cl}^{-}, \mathrm{F}^{-}, \mathrm{Br}^{-}\right.$, and $\left.\mathrm{OH}^{-}\right)$.

Starting geometries of the molecular systems were modeled using Spartan's graphical model builder and minimized interactively using the Sybyl force field [28]. All geometries were fully optimized without any symmetry constraints. A normal mode analysis was performed to verify the nature of the stationary points. Equilibrium geometries were characterized by the absence of imaginary frequencies. The transition state structures were located by a series of constrained geometry optimizations in which the forming, and breaking, of bonds was fixed at various lengths while the remaining internal coordinates were optimized.

The approximate stationary points located from such a procedure were then fully optimized using the standard transition state optimization procedure in Spartan. All firstorder saddle points were shown to have a Hessian matrix with a single negative eigenvalue, characterized by an imaginary vibrational frequency along the reaction coordinate.

This study reports all Gibbs free-energy values unless otherwise noted, at a temperature of $298.15 \mathrm{~K}$ and pressure of $1 \mathrm{~atm}$ using unscaled frequencies.

\section{Results and Discussion}

The recomputed density functional theory (DFT) optimized structures of $\mathrm{ReO}_{4}{ }^{-}$and $\mathrm{ReO}_{3} \mathrm{Cl}$ on a singlet potential energy surface are shown in Figures S1 and S2. The energetics and the nature of stationary points agree with those computed previously by Aniagyei et al. [16]. As shown in the energy profile diagrams (Figures S1 and S2), the addition of ethylene across the $\mathrm{O}=\mathrm{Re}=\mathrm{O}$ shows both kinetic and thermodynamic preference for the $[3+2]$ pathway over the $[2+2]$ pathway leading to the formation of an oxetane. It is also evident from the profile diagrams (Figure S2) that an epoxide is formed through a rearrangement of the oxetane when the oxidation of ethylene is catalyzed by $\mathrm{ReO}_{3} \mathrm{Cl}$. In all cases, there were no triplet transition states observed.

Mulliken and natural population analysis were performed to estimate the partial atomic charges of each atom of the oxo complexes, and the results are shown in Table 1. The results show that there are general higher natural charges compared to the Mulliken charges. For example, in Table 1, entry 1 is for $\mathrm{ReO}_{3} \mathrm{~F}$, the Mulliken partial charge of $\mathrm{Re}$ is $+2.207, \mathrm{O}$ is -0.544 , and $\mathrm{F}$ is -0.395 while for the natural charge, $\mathrm{Re}$ is $+2.637, \mathrm{O}$ is -0.702 , and $\mathrm{F}$ is -0.530 .

The dipole moments of each oxo complex on both singlet and triplet reaction surfaces are shown in Table 1. It was observed that the oxo complexes on the triplet surfaces had a higher dipole moment compared to their counterparts on the singlet PES. This is accounted for by the change in the molecular structure or geometry; that is, the oxo complexes have their tetrahedron geometry either completely or slightly distorted on the triplet surface (Figure S10). The dipole moment calculated on a singlet potential surface shows an increase in polarity for the ligand order $\mathrm{O}^{-}<\mathrm{Cl}^{-}<\mathrm{F}^{-}<\mathrm{Br}^{-}<\mathrm{I}^{-}<\mathrm{OH}^{-}$. These values also suggest that $\mathrm{ReO}_{3} \mathrm{OH}$ is the most polar catalyst and, hence, will have high solubility when used as a catalyst for the oxidation of ethylene in polar solvents.

The energy profile diagrams obtained from Frontier Molecular Orbital calculations are presented in Figures S3-S8, and the results are presented in Table 2. These diagrams show the nature of electron transfer between the Highest Occupied Molecular Orbital (HOMO) and Lowest Unoccupied Molecular Orbital (LUMO) of rhenium complexes and ethylene. In all the rhenium complexes studied, electrons require more energy to move from the HOMO of the rhenium complexes to the LUMO of the ethylene. In the reverse case, electrons require lesser energy to travel from the HOMO of ethylene to the LUMO of the rhenium complex for oxidation to occur. It is, therefore, concluded that the oxidation of ethylene catalyzed by rhenium-oxo complexes proceeds with the flow of electrons from the HOMO of the ethylene to the LUMO of the oxo complexes except in the case of $\mathrm{ReO}_{4}{ }^{-}$where the electron flow is from the HOMO to the LUMO ethylene (Figure S8 and Table 2: entry 1 ).

3.1. Reaction of Ethylene with $\mathrm{ReO}_{3} \mathrm{~F}$. The relative energies of the main stationary points (reactants, transition states, intermediates, and products) and some optimized structures involved in the reaction between ethylene and $\mathrm{ReO}_{3} \mathrm{~F}$ are shown in Figures 1(a) and 1(b), respectively. The singlet $\mathrm{ReO}_{3} \mathrm{~F}$ species has its three $\mathrm{Re}=\mathrm{O}$ bond lengths at $1.704 \AA$ while the Re-F bond equals $1.804 \AA$. The triplet $\mathrm{ReO}_{3} \mathrm{~F}$ has its Re-F bond length at $1.845 \AA$ and its three $\mathrm{Re}=\mathrm{O}$ bond lengths at $1.808 \AA, 1.695 \AA$, and $1.845 \AA$. The triplet rhenium oxo complex is $65.62 \mathrm{kcal} / \mathrm{mol}$ less stable than its singlet structure.

The concerted [3+2] insertion of the $\mathrm{C}=\mathrm{C}$ bond across the $\mathrm{O}=\mathrm{Re}=\mathrm{O}$ functionality of $\mathrm{ReO}_{3} \mathrm{~F}$ to form a dioxylate has an activation barrier of $35.73 \mathrm{kcal} / \mathrm{mol}$ and shows an endergonicity of $18.25 \mathrm{kcal} / \mathrm{mol}$. These energies are lower compared to the same reaction for $\mathrm{ReO}_{4}{ }^{-}$(Figure S1). The triplet dioxylate is found to be $5.87 \mathrm{kcal} / \mathrm{mol}$ less stable than its singlet dioxylate.

The calculated transition state (structure TS 1A, Scheme $\mathrm{S} 1$ and Figure 1) shows high symmetry and is synchronous to the newly forming C-O bonds (1.876 $\AA$ ). In the singlet product, $\mathrm{Re}=\mathrm{O}$ and Re-F spectator bond lengths are $1.686 \AA$ and $1.851 \AA$, respectively. Both Re-O bond lengths are $1.899 \AA$. Although no transition state was observed on the triplet PES, the triplet product had $\mathrm{Re}=\mathrm{O}$ and Re-F bond lengths equal to $1.700 \AA$ and $1.868 \AA$, respectively, with both Re-O being $1.892 \AA$. 
TABLE 1: Mulliken and natural population analysis as well as the dipole moments of rhenium oxo complexes.

\begin{tabular}{lcccccccccc}
\hline Entry & $\begin{array}{c}\text { Mulliken } \\
\text { population } \\
\text { analysis }\end{array}$ & $\begin{array}{c}\mathrm{Re} \\
\text { electronic } \\
\text { charge }\end{array}$ & $\begin{array}{c}\mathrm{O} \\
\text { electronic } \\
\text { charge }\end{array}$ & $\begin{array}{c}\mathrm{L} \\
\text { electronic } \\
\text { charge }\end{array}$ & $\begin{array}{c}\text { Natural } \\
\text { population } \\
\text { analysis }\end{array}$ & $\begin{array}{c}\mathrm{Re} \\
\text { electronic } \\
\text { charge }\end{array}$ & $\begin{array}{c}\mathrm{O} \\
\text { electronic } \\
\text { charge }\end{array}$ & $\begin{array}{c}\mathrm{L} \\
\text { electronic } \\
\text { charge }\end{array}$ & $\begin{array}{c}\text { Dipole } \\
\text { moment } \\
\text { singlet }\end{array}$ & $\begin{array}{c}\text { Dipole } \\
\text { moment triplet }\end{array}$ \\
\hline 1 & $\mathrm{ReO}_{3} \mathrm{~F}$ & +2.207 & -0.544 & -0.395 & & +2.637 & -0.702 & -0.530 & 0.83 & 1.41 \\
2 & $\mathrm{ReO}_{3} \mathrm{Cl}$ & +1.709 & -0.520 & -0.151 & & +2.364 & -0.664 & -0.372 & 0.75 & 0.81 \\
3 & $\mathrm{ReO}_{3} \mathrm{Br}$ & +1.594 & -0.521 & -0.031 & & +2.318 & -0.667 & -0.319 & 1.20 & 1.66 \\
4 & $\mathrm{ReO}_{3} \mathrm{I}$ & +1.558 & -0.521 & -0.003 & & +2.251 & -0.669 & -0.224 & 1.72 & 2.98 \\
5 & $\mathrm{ReO}_{3} \mathrm{OH}$ & +2.004 & -0.561 & -1.260 & & +2.597 & -0.720 & -0.456 & 2.72 & 3.32 \\
6 & $\mathrm{ReO}_{4}^{-}$ & +1.834 & -0.502 & -0.502 & & +2.530 & -0.882 & -0.882 & 0.70 & 0.52 \\
\hline
\end{tabular}

On the singlet PES, the formation for the metallaoxetane intermediate via the [2+2] pathway has an activation energy of $45.55 \mathrm{kcal} / \mathrm{mol}$ and $19.65 \mathrm{kcal} / \mathrm{mol}$ endergonic. Again, no triplet transition state was observed. The calculated transition state (TS 1C in Scheme S1 and Figure 1) has its newly formed C-O and Re-C bond lengths as $1.904 \AA$ and $2.299 \AA$, respectively. In the singlet product, the two $\mathrm{Re}=\mathrm{O}$ bond lengths were $1.708 \AA$, while the Re-F bond length was $1.862 \AA$ and the Re-O bond length was $1.908 \AA$.

The activation energy for the rearrangement of the rhenaoxetane (singlet surface) into the dioxylate is $61.81 \mathrm{kcal} / \mathrm{mol}$ relative to the energetics of the reactants. No transition state was found for the rearrangement on the triplet surface. Since the activation barrier for the rearrangement of the oxetane to form dioxylate is kinetically hindered due to its high activation barrier, and the direct $[3+2]$ addition forming the dioxylate is the most favored mechanistic pathway.

The formation of an epoxide from the rearrangement of the singlet oxetane (TS 1D in Scheme S1) has an activation energy of $67.47 \mathrm{kcal} / \mathrm{mol}$ and showed an endergonicity of $41.54 \mathrm{kcal} / \mathrm{mol}$. The triplet epoxide product is found to be $13.65 \mathrm{kcal} / \mathrm{mol}$ less stable than the singlet epoxide product. The energetics for the $\mathrm{ReO}_{3} \mathrm{Cl}$ catalyzed epoxidation is favored compared to the $\mathrm{ReO}_{3} \mathrm{~F}$. The potential energy surface of the reaction of $\mathrm{ReO}_{3} \mathrm{~F}$ with ethylene was further explored to locate an epoxide precursor $\left(\mathrm{FO}_{2}-\mathrm{Re}-\mathrm{OC}_{2} \mathrm{H}_{4}\right)(\mathrm{TS} 1 \mathrm{~B}$ in Scheme S1) from the $[2+1]$ pathway. However, no minimum was found, implying that the most favored pathway leading to the formation of the epoxide is the $[2+2]$ pathway. As observed in the mechanism for both $\mathrm{ReO}_{4}{ }^{-}$and $\mathrm{ReO}_{3} \mathrm{Cl}$, the reaction involving $\mathrm{ReO}_{3} \mathrm{~F}$ in the [3+2] pathway is both kinetically and thermodynamically favorable concerning dioxylation.

3.2. Reaction of Ethylene with $\mathrm{ReO}_{3} \mathrm{Br}$. Shown in Figures 2(a) and 2 (b) are the energetics and optimized structures of the reactants, transition states, intermediates, and products involved in the reaction between ethylene and $\mathrm{ReO}_{3} \mathrm{Br}$, respectively. The singlet $\mathrm{ReO}_{3} \mathrm{Br}$-optimized species has three $\mathrm{Re}=\mathrm{O}$ bond lengths equal to $1.705 \AA$ while the $\mathrm{Re}-\mathrm{Br}$ bond length equals $2.409 \AA$. The optimized triplet $\mathrm{ReO}_{3} \mathrm{Br}$ has a $\mathrm{Re}-\mathrm{Br}$ bond length of $2.404 \AA$, and its three $\mathrm{Re}=\mathrm{O}$ bond lengths were $1.808 \AA$, $1.692 \AA$, and $1.808 \AA$, respectively. The triplet rhenium oxo complex is $65.009 \mathrm{kcal} / \mathrm{mol}$ less stable than its singlet structure.
The concerted [3+2] addition of the $\mathrm{C}=\mathrm{C}$ bond across the $\mathrm{O}=\mathrm{Re}=\mathrm{O}$ functionality of $\mathrm{ReO}_{3} \mathrm{Br}$ to form a dioxylate intermediate has an activation barrier of $34.87 \mathrm{kcal} / \mathrm{mol}$ and shows an endergonicity of $16.60 \mathrm{kcal} / \mathrm{mol}$. No transition state was located on the triplet PES. The triplet dioxylate, in this case, was found to be $4.61 \mathrm{kcal} / \mathrm{mol}$ less stable than its singlet. The transition state structure is highly symmetrical and has its C-O bond lengths as $1.883 \AA$.

The $[2+2]$ singlet pathway has an activation barrier of $48.96 \mathrm{kcal} / \mathrm{mol}$ and shows an endergonicity of $21.52 \mathrm{kcal} /$ mol. No triplet transition state was observed for the formation of the metallaoxetane intermediate. The formation of the dioxylate intermediate via the $[2+2]$ pathway has an activation of $63.17 \mathrm{kcal} / \mathrm{mol}$ relative to the energetics of the reactants on a single PES. No triplet transition state was found for the rearrangement.

The $[3+2]$ pathway was the most plausible route in forming diols. However, the formation of an epoxide is not plausible on both the singlet and triplet surfaces because no such saddle point structures (TS $1 \mathrm{~B}$ and TS $1 \mathrm{D}$ in Scheme S1) were found. This means that no side reactions are competing with the formation of the dioxylate and metallaoxetane intermediates.

3.3. Reaction of Ethylene with $\mathrm{ReO}_{3} \mathrm{I}$. The relative energies and optimized structures involved in the reaction between ethylene and $\mathrm{ReO}_{3} \mathrm{I}$ are shown in Figure 3(a) and 3(b), respectively. The singlet optimized $\mathrm{ReO}_{3} \mathrm{I}$ structure has its three $\mathrm{Re}=\mathrm{O}$ bond lengths at $1.706 \AA$, while the $\mathrm{Re}-\mathrm{I}$ bond length is $2.625 \AA$. The triplet ReO3I has a Re-I bond length of $1.845 \AA$, and the three $\mathrm{Re}=\mathrm{O}$ bond lengths are $1.705 \AA$, $1.845 \AA$, and $1.706 \AA$. The triplet rhenium oxo complex is $52.86 \mathrm{kcal} / \mathrm{mol}$ less stable than its singlet structure.

The oxidation of the $\mathrm{C}=\mathrm{C}$ bond by $\mathrm{ReO}_{3} \mathrm{I}$ to form a dioxylate intermediate has an activation barrier of $35.78 \mathrm{kcal} / \mathrm{mol}$ and showed an endergonicity of $17.34 \mathrm{kcal} / \mathrm{mol}$. No transition state was located on the triplet PES. A triplet dioxylate intermediate was found to be $3.63 \mathrm{kcal} / \mathrm{mol}$ less stable than its singlet dioxylate. The transition state is symmetrical, and the newly forming $\mathrm{C}$ - $\mathrm{O}$ bond length is $1.880 \AA$. The spectator bonds ( $\mathrm{Re}=\mathrm{O}$ and a Re-I) of the dioxylate intermediate have bond lengths of $1.682 \AA$ and $2.620 \AA$, respectively, and the Re-O bond length was $1.901 \AA$. The formation of a metallaoxetane has an activation barrier of $49.10 \mathrm{kcal} / \mathrm{mol}$ with an endergonicity value of $21.30 \mathrm{kcal} / \mathrm{mol}$. No transition 
TABle 2: The Frontier Molecular Orbitals calculation for the rhenium oxo complexes.

\begin{tabular}{|c|c|c|c|c|c|c|c|c|}
\hline Entry & $\begin{array}{l}\text { Singlet } \\
\text { reactants }\end{array}$ & $\begin{array}{c}\mathrm{HOMO} / \\
\mathrm{eV}\end{array}$ & $\begin{array}{c}\text { LUMO/ } \\
\mathrm{eV}\end{array}$ & $\begin{array}{c}\mathrm{HOMO} / \mathrm{eV} \\
\text { ethene }\end{array}$ & $\begin{array}{l}\mathrm{LUMO} / \mathrm{eV} \\
\text { ethene }\end{array}$ & $\begin{array}{c}\text { HOMO-LUMO/eV } \\
\text { metal-ethylene } \\
\text { bonding }\end{array}$ & $\begin{array}{c}\text { HOMO-LUMO/eV } \\
\text { ethylene-metal } \\
\text { bonding }\end{array}$ & Nature of bonding \\
\hline 1 & $\mathrm{ReO}_{4}^{-}$ & -2.99 & 3.47 & -7.26 & 0.51 & 10.70 & 3.50 & Reverse \\
\hline 2 & $\mathrm{ReO}_{3} \mathrm{~F}$ & -9.75 & -3.70 & -7.26 & 0.51 & 3.56 & 10.26 & Normal \\
\hline 3 & $\mathrm{ReO}_{3} \mathrm{Cl}$ & -9.82 & -3.97 & -7.26 & 0.51 & 3.97 & 10.33 & Normal \\
\hline 4 & $\mathrm{ReO}_{3} \mathrm{Br}$ & -9.41 & -3.91 & -7.26 & 0.51 & 3.35 & 9.92 & Normal \\
\hline 5 & $\mathrm{ReO}_{3} \mathrm{I}$ & -8.61 & -3.87 & -7.26 & 0.51 & 3.39 & 9.12 & Normal \\
\hline 6 & $\mathrm{ReO}_{3} \mathrm{OH}$ & -9.30 & -3.39 & -7.26 & 0.51 & 3.87 & 9.81 & Normal \\
\hline
\end{tabular}

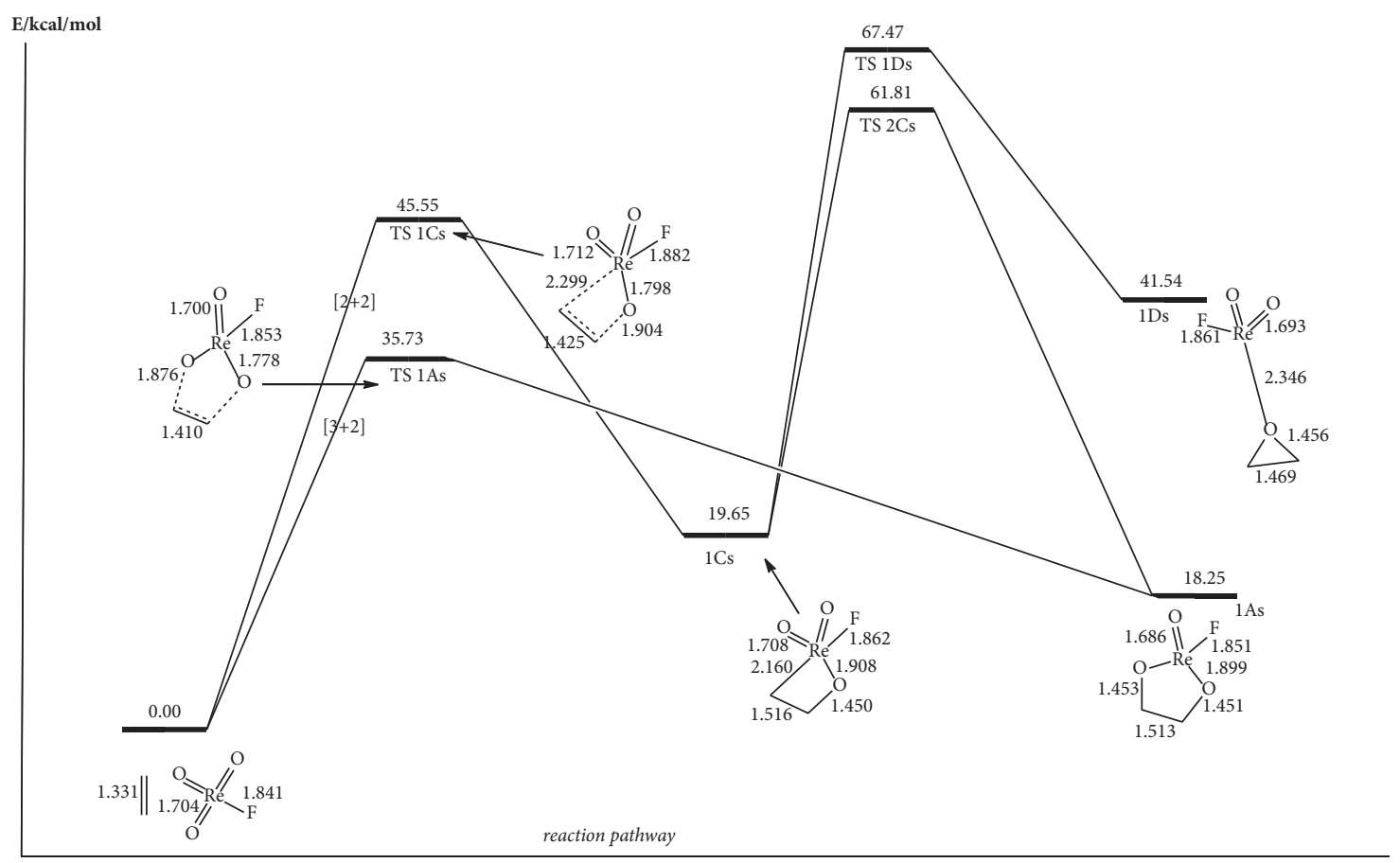

(a)

Figure 1: Continued. 


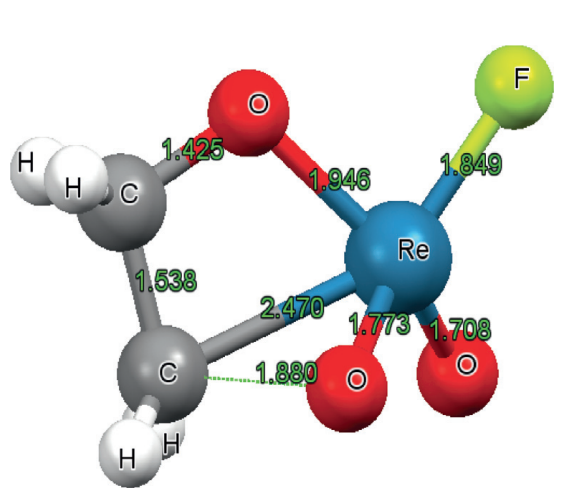

TS 2Cs

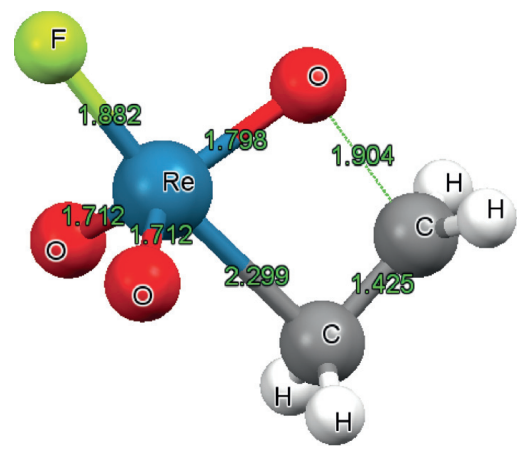

TS $1 \mathrm{Cs}$

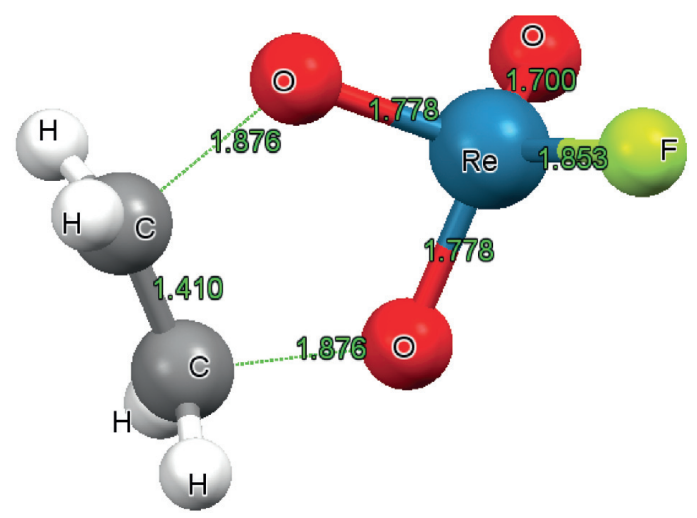

TS 1As

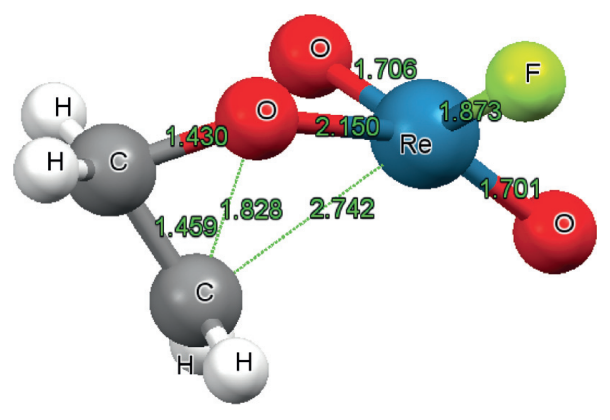

TS 1Ds

(b)

Figure 1: (a) Gibbs free-energy profile diagram for the reaction between $\mathrm{ReO}_{3} \mathrm{~F}$ and ethylene at the B3LYP/LACVP* level of theory. (b) Optimized transition states involved in the reaction between $\mathrm{ReO}_{3} \mathrm{~F}$ and ethylene at the $\mathrm{B} 3 \mathrm{LYP} / \mathrm{LACVP}$ (evel of theory.

state for the formation of the metallaoxetane was found on the triplet PES. The calculated transition state (TS 1C in Scheme S1) has its newly forming $\mathrm{C}-\mathrm{O}$ and $\mathrm{Re}-\mathrm{C}$ bonds at $2.321 \AA$ and $1.907 \AA$, respectively. In the metallaxetane, the two $\mathrm{Re}=\mathrm{O}$ and $\mathrm{Re}-\mathrm{I}$ spectator bond lengths are $1.708 \AA$, and $2.719 \AA$, respectively, and the $\mathrm{Re}-\mathrm{O}$ bond length is $1.811 \AA$. The activation energy for the rearrangement of the metallaoxetane (singlet surface) into the dioxylate is $63.40 \mathrm{kcal} / \mathrm{mol}$ relative to the energetics of the reactants. No transition state was found for the rearrangement on the triplet PES. As observed with $\mathrm{ReO}_{3} \mathrm{Br}$, the formation of epoxide is not plausible with $\mathrm{ReO}_{3} \mathrm{I}$.

3.4. Reaction of Ethylene with $\mathrm{ReO}_{3} \mathrm{OH}$. The relative energies of the main stationary points (reactants, transition states, intermediates, and products) and some optimized structures involved in the reaction between ethylene and $\mathrm{ReO}_{3} \mathrm{OH}$ are shown in Figures 4(a) and 4(b), respectively. The singlet $\mathrm{ReO}_{3} \mathrm{OH}$ optimized species has all its three $\mathrm{Re}=\mathrm{O}$ bond lengths equal to $1.709 \AA$, while the $\mathrm{Re}-\mathrm{OH}$ bond length equals $1.878 \AA$. The triplet $\mathrm{ReO}_{3} \mathrm{OH}$ has a $\mathrm{Re}-\mathrm{OH}$ bond length of $1.870 \AA$, and its three $\mathrm{Re}=\mathrm{O}$ bond lengths were $1.813 \AA, 1.699 \AA$, and $1.843 \AA$, with a slightly distorted tetrahedron geometry. The triplet rhenium oxo complex is $64.65 \mathrm{kcal} / \mathrm{mol}$ less stable than its singlet structure.
The formation of a dioxylate (structure 1A in Scheme S1) through the insertion of the $\mathrm{C}=\mathrm{C}$ bond across the $\mathrm{O}=\mathrm{Re}=\mathrm{O}$ of $\mathrm{ReO}_{3} \mathrm{OH}$ functionality has an activation barrier of $38.20 \mathrm{kcal} / \mathrm{mol}$ and shows an endergonicity of $20.82 \mathrm{kcal} /$ mol. No transition state was located on the PES. A triplet dioxylate was found to be $4.70 \mathrm{kcal} / \mathrm{mol}$ less stable than its singlet. The calculated transient (structure TS 1A in Scheme S1) shows high symmetry, and it is synchronous to the newly forming C-O bond with a bond length of $1.870 \AA$. The $\mathrm{Re}=\mathrm{O}$ and $\mathrm{Re}-\mathrm{OH}$ spectator bond lengths were $1.690 \AA$ and $1.882 \AA$, respectively, and the $\mathrm{Re}-\mathrm{O}$ bond length was $1.905 \AA$. In the triplet product, however, the $\mathrm{Re}=\mathrm{O}$ and $\mathrm{Re}$ OH spectator bond lengths were $1.706 \AA$ and $1.903 \AA$, respectively, and the $\mathrm{Re}=\mathrm{O}$ bond length was $1.930 \AA$.

The [2+2] pathway has an activation barrier of $49.25 \mathrm{kcal} / \mathrm{mol}$ and shows an endergonicity of $20.05 \mathrm{kcal} /$ mol. No triplet transition state for the formation of the metallaoxetane was observed on the triplet PES. The calculated transition state (TS $1 \mathrm{C}$ in Scheme S1) has its C-O and Re-C bond lengths as $2.331 \AA$ and $1.779 \AA$, respectively. In the singlet product, the two $\mathrm{Re}=\mathrm{O}$ and $\mathrm{Re}-\mathrm{OH}$ spectator bond lengths are $1.731 \AA$ and $1.908 \AA$ and the Re-O bond length is $1.961 \AA$. The rearrangement of the singlet oxetane has an activation energy of $62.88 \mathrm{kcal} / \mathrm{mol}$ relative to the energetics of the reactants. No transition state was found for the rearrangement on the triplet PES. In this case, the $[3+2]$ 


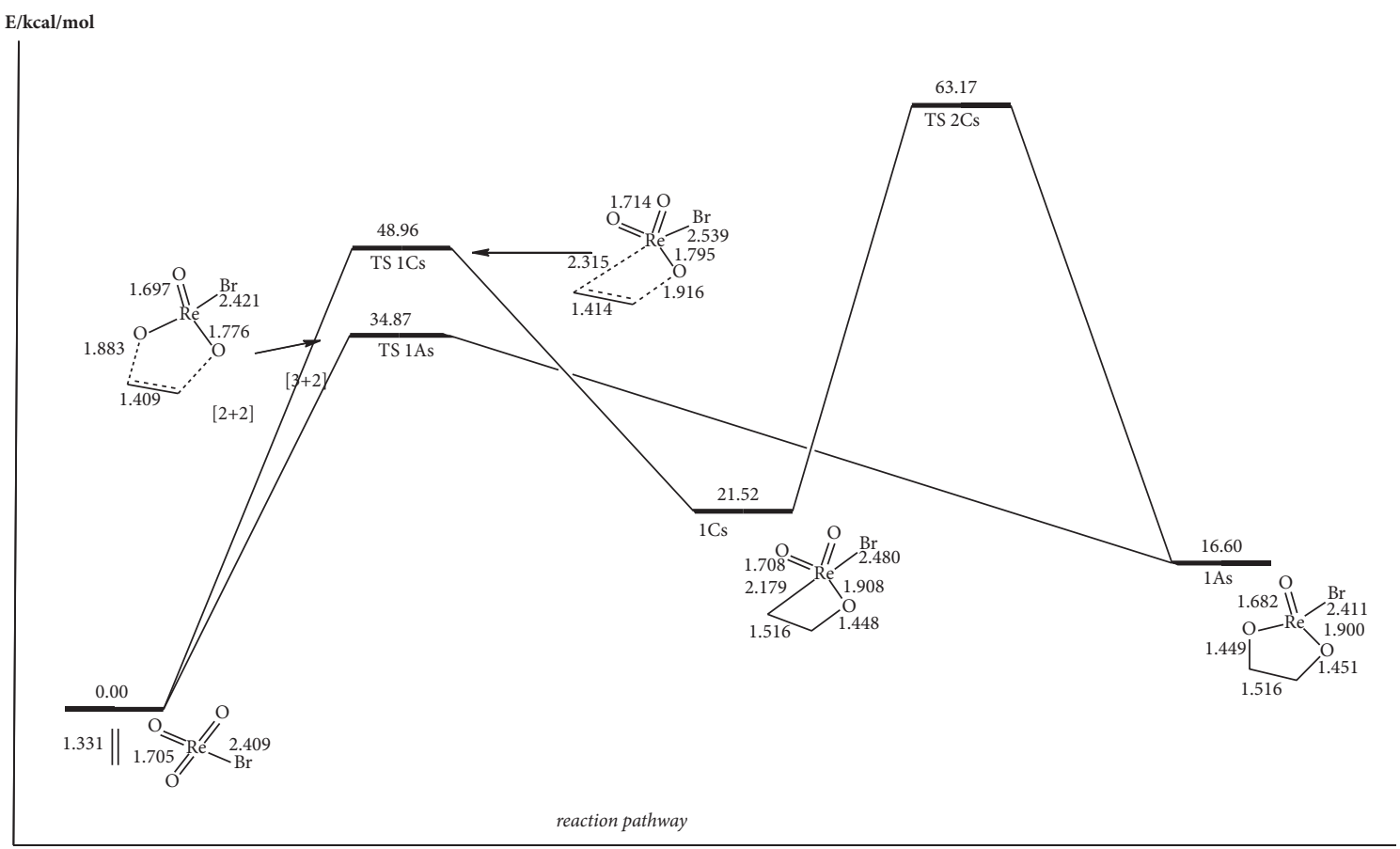

(a)

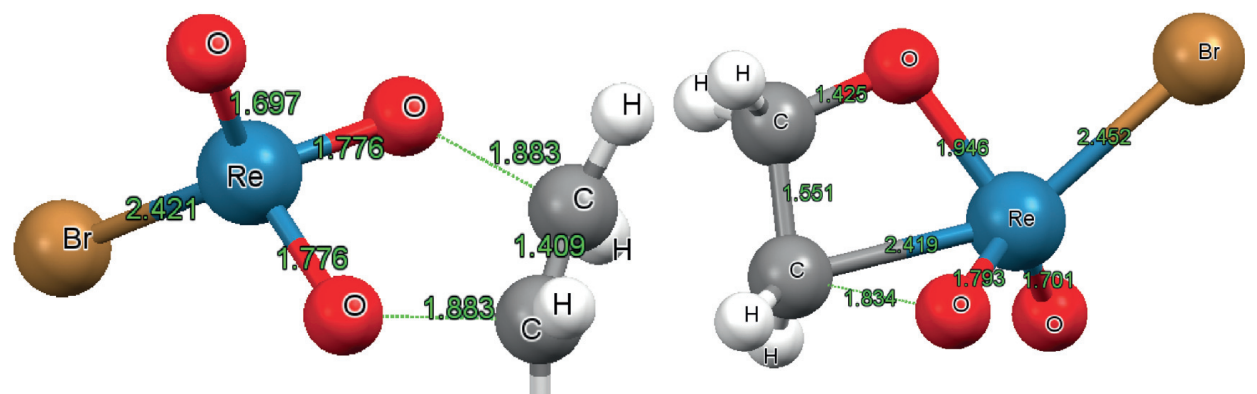

H.

TS 2Cs

TS 1As

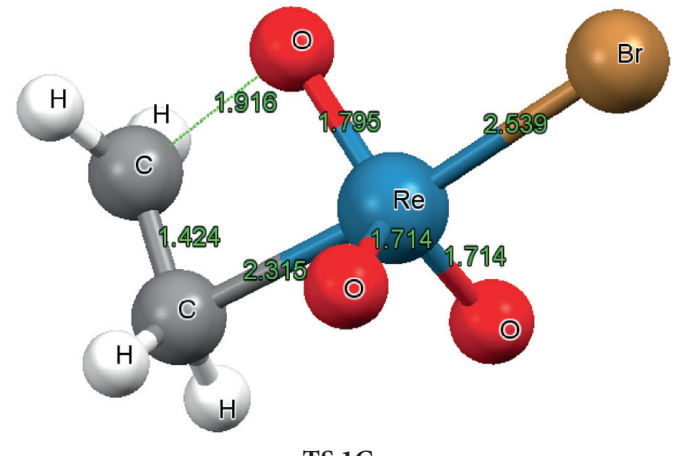

TS 1Cs

(b)

FIGURE 2: (a) Gibbs free-energy profile diagram for the reaction between $\mathrm{ReO}_{3} \mathrm{Br}$ and ethylene at the B3LYP/LACVP* level of theory. (b) Optimized transition states involved in the reaction between $\mathrm{ReO}_{3} \mathrm{Br}$ and ethylene at the B3LYP/LACVP* level of theory. 


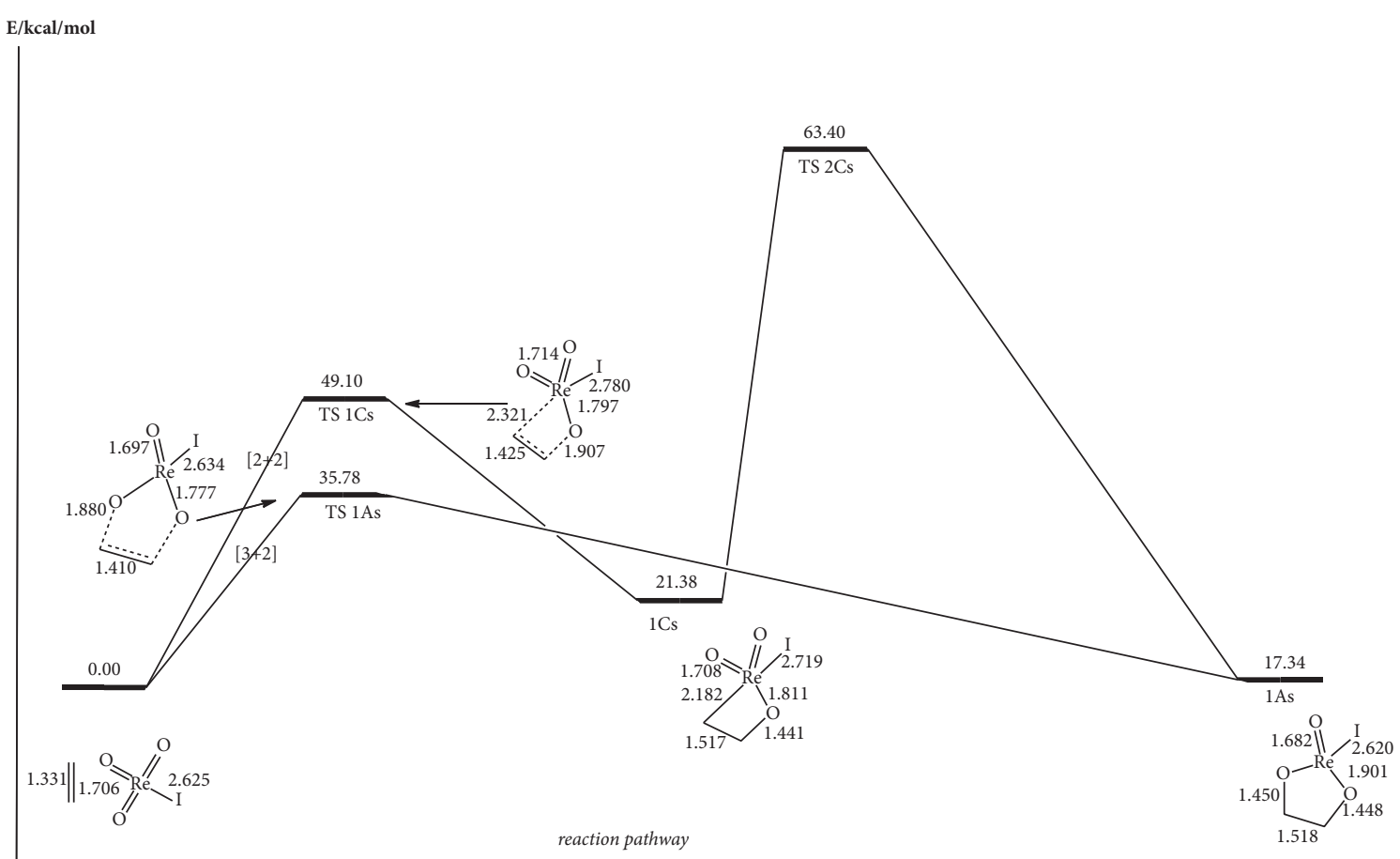

(a)
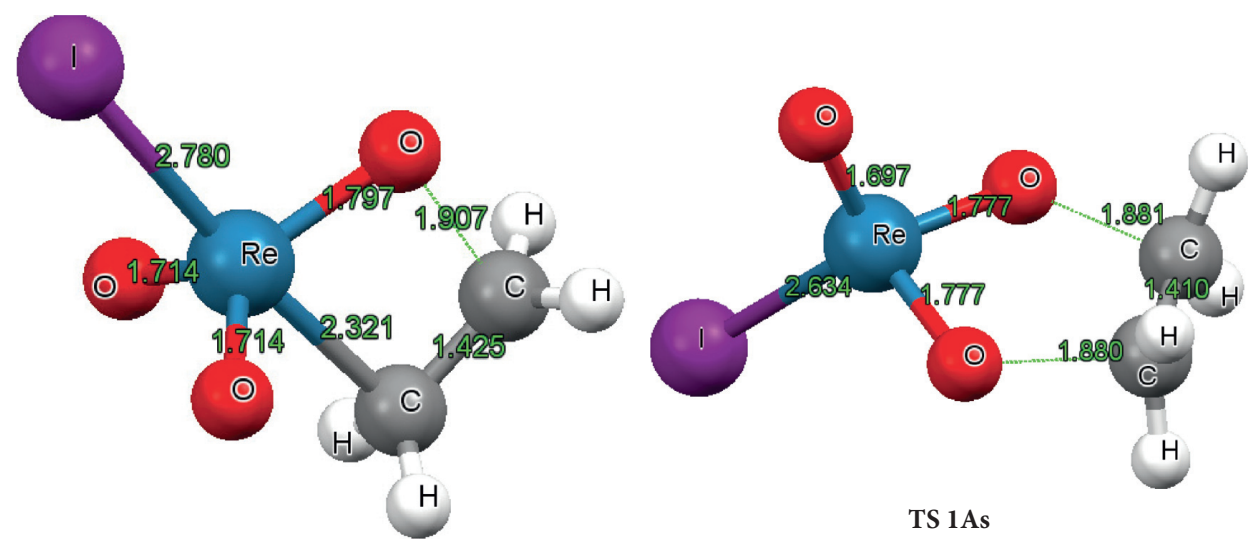

TS 1As

TS 2Cs

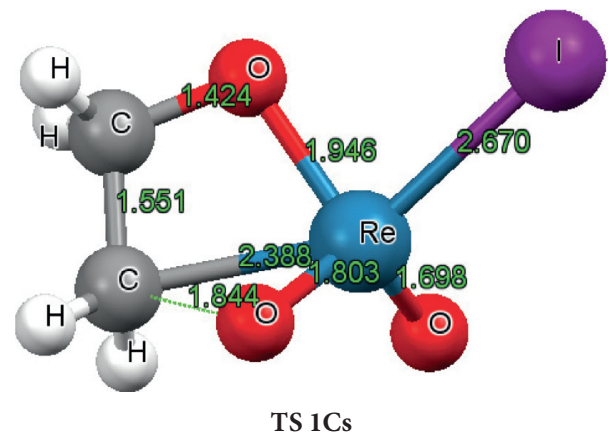

(b)

Figure 3: (a) Gibbs free-energy profile diagram for the reaction between $\mathrm{ReO}_{3} \mathrm{I}$ and ethylene at the B3LYP/LACVP* level of theory. (b) Optimized transition states involved in the reaction between $\mathrm{ReO}_{3} \mathrm{I}$ and ethylene at the $\mathrm{B} 3 \mathrm{LYP} / \mathrm{LACVP}^{*}$ level of theory. 


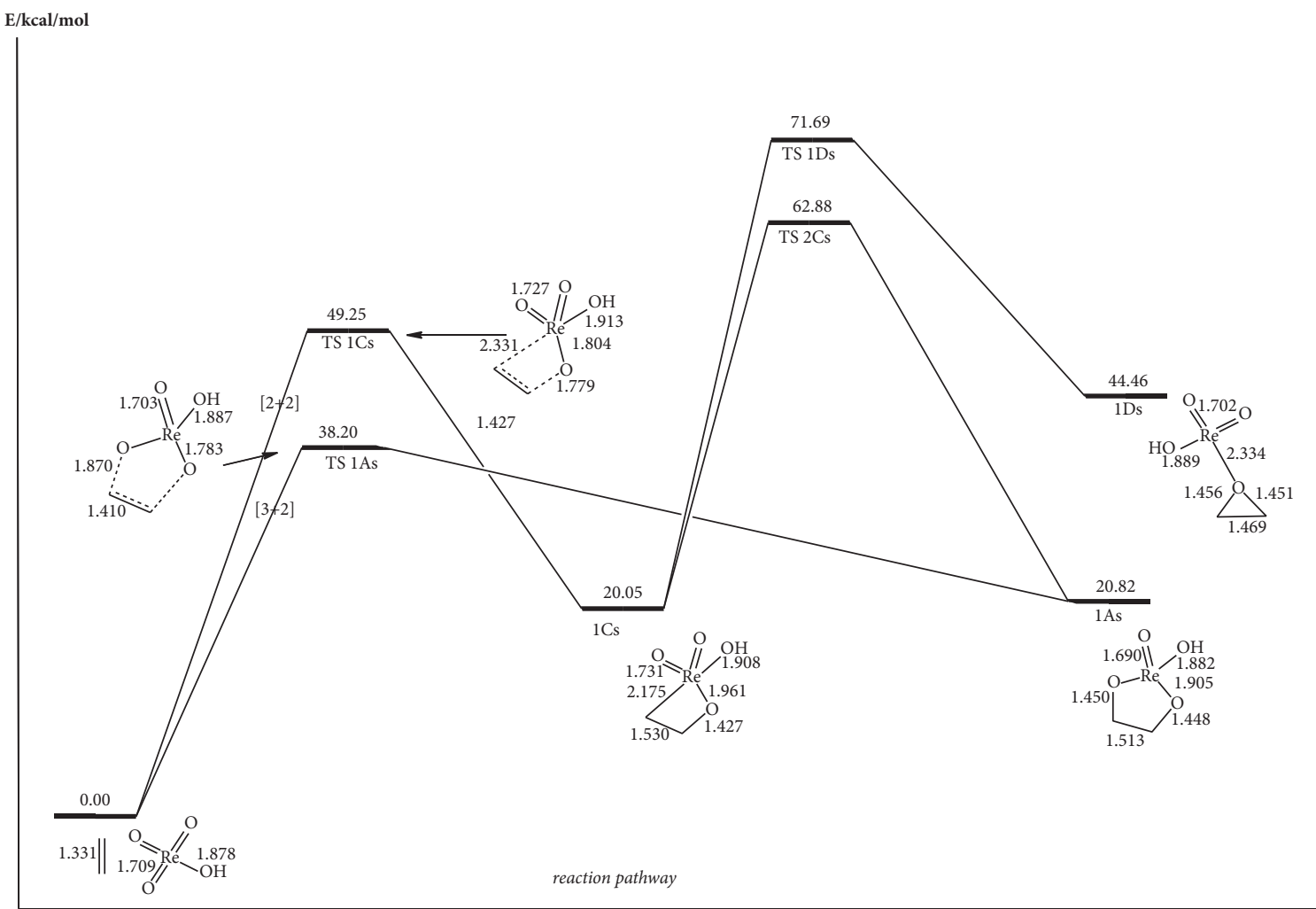

(a)

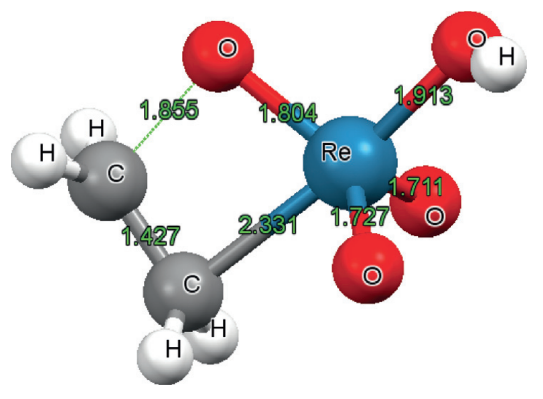

TS 1Cs

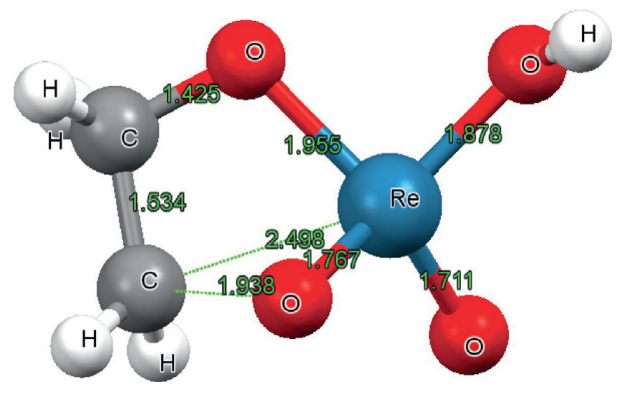

TS 2Cs

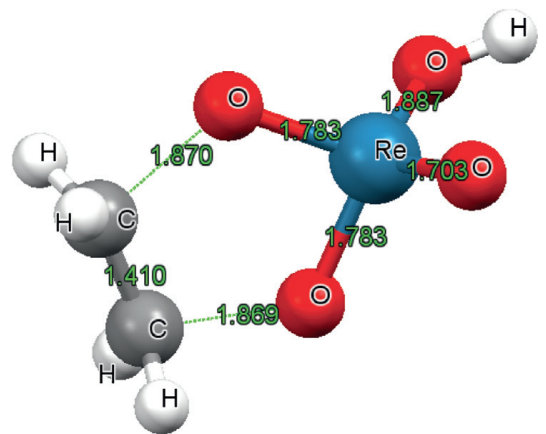

TS 1As

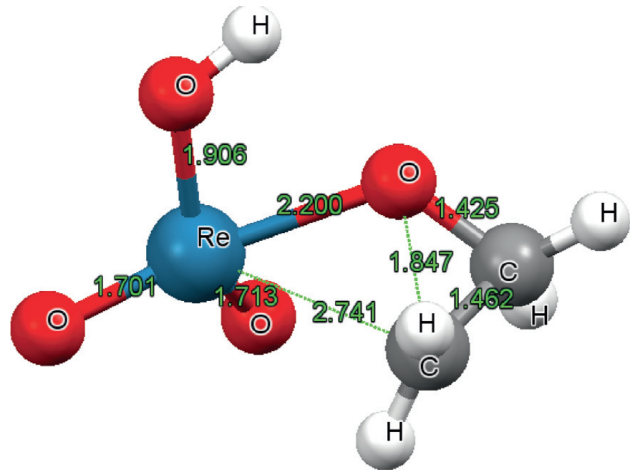

TS 1Ds

(b)

FiguRE 4: (a) Gibbs free-energy profile diagram for the reaction between $\mathrm{ReO}_{3} \mathrm{OH}$ and ethylene at the B3LYP/LACVP* level of theory. (b) Optimized transition states involved in the reaction between $\mathrm{ReO}_{3} \mathrm{OH}$ and ethylene at the B3LYP/LACVP* level of theory. 
mechanistic pathway is the most plausible route to form the dioxylate. In the exploration of the formation of an epoxide precursor (TS 1D in Scheme S1) from the rearrangement of the oxetane, an activation barrier of $58.55 \mathrm{kcal} / \mathrm{mol}$ was observed with an equivalent endergonicity value of $71.69 \mathrm{kcal} / \mathrm{mol}$. A triplet epoxide was found to be $12.19 \mathrm{kcal} /$ mol less stable than the singlet epoxide.

The potential energy surface of the reaction of $\mathrm{ReO}_{3} \mathrm{OH}$ with ethylene was then explored to locate an epoxide precursor $\left(\mathrm{HOO}_{2}-\mathrm{Re}-\mathrm{OC}_{2} \mathrm{H}_{4}\right)$ [TS $1 \mathrm{~B}$ in Scheme S1] from the direct addition of the ethylene to the oxo complex $[2+1]$, but no such minima were found on the reaction surface making the $[2+2]$ pathway the most favorable one leading to the formation of the epoxide.

The optimized singlet and triplet structures of for the involved reaction mechanism are shown in Figure S9 to Figure S15.

\section{Conclusions}

The results of this study show that the $[3+2]$ mechanistic pathway is both kinetically and thermodynamically favored for the formation of dioxylate. Comparing the catalysts studied in the manuscript to $\mathrm{ReO}_{4}{ }^{-}$and $\mathrm{ReO}_{3} \mathrm{Cl}$ studied by Aniagyei et al. [16], the $\mathrm{ReO}_{3} \mathrm{Cl}$ catalyst is the best for the dioxylate transformation. The activation energies for the formation of the dioxylate follow the ligand order $\mathrm{O}^{-}>\mathrm{OH}^{-}>\mathrm{I}^{-}>\mathrm{F}^{-}>\mathrm{Br}^{-}>\mathrm{Cl}^{-}$. The hydroxylation ability of the catalysts decreases down the group of the halogens except for the fluorine ligand. In the case where epoxide formation is possible, it goes through the $[2+2]$ mechanistic pathway. Among the catalyst studied, only $\mathrm{ReO}_{3} \mathrm{~F}, \mathrm{ReO}_{3} \mathrm{Cl}$ and $\mathrm{ReO}_{3} \mathrm{OH}$ showed potential epoxidation catalytic ability, with $\mathrm{ReO}_{3} \mathrm{~F}$ being the best. The electron flow for the oxidation reactions occurs from the HOMO of ethylene to the LUMO of the rhenium oxo complexes in all cases except for $\mathrm{ReO}_{4}{ }^{-}$where vice versa occurs. For the $\mathrm{ReO}_{4}{ }^{-}, \mathrm{ReO}_{3} \mathrm{I}$, and $\mathrm{ReO}_{3} \mathrm{Br}$ reaction surfaces, no side reactions are competing with the formation of the dioxylate and metallaoxetane intermediates. The polarity of the complexes studied shows that $\mathrm{ReO}_{3} \mathrm{OH}$ is the most polar with $\mathrm{ReO}_{3} \mathrm{I}$ having the highest polarity for the halogen ligands. That means, $\mathrm{ReO}_{3} \mathrm{OH}$ when used as a catalyst to oxidize ethylene to vicinal diols will show high catalytic activity in polar solvents due to its high solubility.

\section{Data Availability}

The data are given in the supplementary document attached to the manuscript for submission.

\section{Conflicts of Interest}

The authors declare no conflicts of interest.

\section{Acknowledgments}

The authors acknowledge the University of Ghana for financial support, the University of Johannesburg for allowing to use the Spartan cluster, and the Centre for High-Performance Computing (CHPC-South Africa) for allowing to use the cluster.

\section{Supplementary Materials}

Scheme S1: the proposed concerted addition mechanistic pathway for the reaction of $\mathrm{ReO}_{3} \mathrm{~L}\left(\mathrm{~L}=\mathrm{O}^{-}, \mathrm{Cl}-, \mathrm{F}^{-}, \mathrm{Br}, \mathrm{I}^{-}\right.$, and $\mathrm{OH}^{-}$) with ethylene. Figure $\mathrm{S} 1$ : energy profile diagram for the reaction between $\mathrm{ReO}_{4}{ }^{-}$and ethylene using B3LYP/ LACVP* level of theory. Figure S2: energy profile diagram for the reaction between $\mathrm{ReO}_{3} \mathrm{Cl}$ and ethylene using B3LYP/

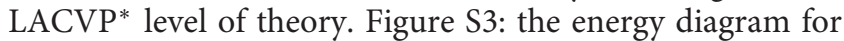
the movement of electrons between the HOMO and LUMO of $\mathrm{ReO}_{3} \mathrm{Cl}$ and ethylene using B3LYP/LACVP* level of theory. Figure S4: the energy diagram for the movement of electrons between the HOMO and LUMO of $\mathrm{ReO}_{3} \mathrm{~F}$ and ethylene using B3LYP/LACVP* level of theory. Figure S5: the energy diagram for the movement of electrons between the $\mathrm{HOMO}$ and LUMO of $\mathrm{ReO}_{3} \mathrm{Br}$ and ethylene using B3LYP/LACVP* level of theory. Figure S6: the energy diagram for the movement of electrons between the HOMO and LUMO of $\mathrm{ReO}_{3} \mathrm{I}$ and ethylene using B3LYP/LACVP* level of theory. Figure S7: the energy diagram for the movement of electrons between the HOMO and LUMO of $\mathrm{ReO}_{3} \mathrm{OH}$ and ethylene using B3LYP/LACVP* level of theory. Figure S8: the energy diagram for the movement of electrons between the HOMO and LUMO of $\mathrm{ReO}_{4}{ }^{-}$and ethylene using B3LYP/LACVP* level of theory. Figure S9: optimized singlet structures of the reactants involved between $\mathrm{ReO}_{3} \mathrm{~L}\left(\mathrm{~L}=\mathrm{O}^{-}, \mathrm{Cl}^{-}, \mathrm{F}^{-}, \mathrm{OH}^{-}, \mathrm{Br}^{-}\right.$, and $\left.\mathrm{I}^{-}\right)$and ethene. Figure S10: optimized triplet structures of the reactants involved between $\mathrm{ReO}_{3} \mathrm{~L}\left(\mathrm{~L}=\mathrm{O}^{-}, \mathrm{Cl}^{-}, \mathrm{F}^{-}, \mathrm{OH}^{-}, \mathrm{Br}^{-}\right.$, and $\left.\mathrm{I}^{-}\right)$ and ethene. Figure S11: optimized dioxylate involved in the reaction between $\mathrm{ReO}_{3} \mathrm{~L}\left(\mathrm{~L}=\mathrm{O}^{-}, \mathrm{Cl}^{-}, \mathrm{F}^{-}, \mathrm{OH}^{-}, \mathrm{Br}^{-}\right.$, and $\left.\mathrm{I}^{-}\right)$ and ethene on the singlet PES. Figure S12: optimized dioxylate of the reaction involved between $\mathrm{ReO}_{3} \mathrm{~L}\left(\mathrm{~L}=\mathrm{O}^{-}\right.$, $\mathrm{Cl}^{-}, \mathrm{F}^{-}, \mathrm{OH}^{-}, \mathrm{Br}^{-}$, and $\mathrm{I}^{-}$) and ethene on the triplet PES. Figure S13: optimized oxetane involved in the reaction between $\mathrm{ReO}_{3} \mathrm{~L}\left(\mathrm{~L}=\mathrm{O}^{-}, \mathrm{Cl}^{-}, \mathrm{F}^{-}, \mathrm{OH}^{-}, \mathrm{Br}^{-}\right.$, and $\left.\mathrm{I}^{-}\right)$and ethene on the singlet PES. Figure S14: optimized oxetane involved in the reaction between $\mathrm{ReO}_{3} \mathrm{~L}\left(\mathrm{~L}=\mathrm{O}^{-}, \mathrm{Cl}^{-}, \mathrm{F}^{-}\right.$, $\mathrm{OH}^{-}, \mathrm{Br}^{-}$, and $\mathrm{I}^{-}$) and ethene on the triplet PES. Figure S15: optimized epoxide structures involved in the reaction between $\mathrm{ReO}_{3} \mathrm{~L}\left(\mathrm{~L}=\mathrm{O}^{-}, \mathrm{Cl}^{-}, \mathrm{F}^{-}, \mathrm{OH}^{-}, \mathrm{Br}^{-}\right.$, and $\left.\mathrm{I}^{-}\right)$and ethene on the singlet PES. Figure S16: optimized epoxide structures involved in the reaction between $\mathrm{ReO}_{3} \mathrm{~L}\left(\mathrm{~L}=\mathrm{O}^{-}, \mathrm{Cl}^{-}, \mathrm{F}^{-}\right.$, $\mathrm{OH}^{-}, \mathrm{Br}^{-}$, and $\mathrm{I}^{-}$) and ethene on the triplet PES. (Supplementary Materials)

\section{References}

[1] A. Dauth and J. A. Love, "Reactivity by design-metallaoxetanes as centerpieces in reaction development," Chemical Reviews, vol. 111, no. 3, pp. 2010-2047, 2011.

[2] D. V. Deubel, "Reactivity of osmium tetraoxide towards nitrogen heterocycles: implications for the molecular recognition of DNA mismatch," Angewandte Chemie International Edition, vol. 42, no. 17, pp. 1974-1977, 2003. 
[3] D. V. Deubel and G. Frenking, "[3 + 2] versus [2+2] addition of metal oxides across CC bonds. reconciliation of experiment and theory," Accounts of Chemical Research, vol. 36, no. 9, pp. 645-651, 2003.

[4] M. Schroeder, "Osmium tetraoxide CIS hydroxylation of unsaturated substrates," Chemical Reviews, vol. 80, no. 2, pp. 187-213, 1980.

[5] H. C. Kolb, M. S. VanNieuwenhze, and K. B. Sharpless, "Catalytic asymmetric dihydroxylation," Chemical Reviews, vol. 94, no. 8, pp. 2483-2547, 1994.

[6] R. Tia and E. Adei, "[3+2] versus [2+2] addition of metal oxides across CC bonds: a theoretical study of the mechanisms of oxidation of ethylene by osmium oxide complexes," Computational and Theoretical Chemistry, vol. 977, no. 1-3, pp. 140-147, 2011.

[7] C. B. Khouw, J. A. Labinger, and M. E. Davis, "Studies on the catalytic-oxidation of alkanes and alkenes by titanium silicates," Journal of Catalysis, vol. 149, no. 1, pp. 195-205, 1994.

[8] H. Mimoun, M. Mignard, P. Brechot, and L. Saussine, "Selective epoxidation of olefins by oxo[N-(2-oxidophenyl)salicylidenaminato]vanadium $(\mathrm{V})$ alkylperoxides. On the mechanism of the halcon epoxidation process," Journal of the American Chemical Society, vol. 108, no. 13, pp. 3711-3718, 1986.

[9] K. B. Sharpless, A. Y. Teranishi, and J. E. Bäckvall, "Chromyl chloride oxidations of olefins. possible role of organometallic intermediates in the oxidations of olefins by oxo transition metal species," Journal of the American Chemical Society, vol. 99, no. 9, pp. 3120-3128, 1977.

[10] D. G. Lee, "Phase transfer assisted permanganate oxidations," Organic Chemistry, vol. 5, pp. 147-206, 1982.

[11] M. A. Pietsch, T. V. Russo, R. B. Murphy, R. L. Martin, and A. K. Rappé, "LReO3Epoxidizes,cis-Dihydroxylates, and cleaves alkenes as well as alkenylates aldehydes: toward an understanding of why," Organometallics, vol. 17, no. 13, pp. 2716-2719, 1998.

[12] D. W. Nelson, A. Gypser, P. T. Ho et al., "Toward an understanding of the high enantioselectivity in the osmiumcatalyzed asymmetric dihydroxylation. 4. Electronic effects in amine-accelerated osmylations," Journal of the American Chemical Society, vol. 119, no. 8, pp. 1840-1858, 1997.

[13] W. A. Herrmann and F. E. Kühn, "Organorhenium oxides," Accounts of Chemical Research, vol. 30, no. 4, pp. 169-180, 1997.

[14] W. A. Herrmann, P. W. Roesky, M. Wang, W. Scherer, and "W. A. Herrmann, "Multiple bonds between main-group elements and transition metals. 135. oxorhenium(v) catalysts for the olefination of aldehydes," Organometallics, vol. 3, no. 9, pp. 4531-4535, 1994.

[15] C. C. Romão, F. E. Kühn, and W. A. Herrmann, "Rhenium(VII) oxo and imido complexes: synthesis, structures, and applications," Chemical Reviews, vol. 97, no. 8, pp. 3197-3246, 1997.

[16] A. Aniagyei, R. Tia, and E. Adei, "A density functional theory study of the mechanisms of oxidation of ethylene by rhenium oxide complexes," Dalton Transactions, vol. 42, Article ID 10885, 97 pages, 2013.

[17] P. Gisdakis, S. Antonczak, and N. Rösch, "Thermochemistry of oxygen transfer between rhenium and phosphine complexes," Organometallics, vol. 18, no. 24, pp. 5044-5056, 1999.

[18] A. D. Becke, "Density-functional thermochemistry. III. The role of exact exchange," The Journal of Chemical Physics, vol. 98, no. 7, pp. 5648-5652, 1993.
[19] D. V. Deubel and G. Frenking, "Are there metal oxides that prefer a [2+2] addition over a [3+2] addition to Olefins? Theoretical study of the reaction," Journal of the American Chemical Society, vol. 121, pp. 2021-2031, 1999.

[20] P. Gisdakis and N. Rösch, "[2+3] cycloaddition of ethylene to transition metal oxo compounds. Analysis of density functional results by Marcus theory," Journal of the American Chemical Society, vol. 123, no. 4, pp. 697-701, 2001.

[21] A. L. Buchachenko, "Recent advances in spin chemistry," Pure and Applied Chemistry, vol. 72, no. 12, pp. 2243-2258, 2000.

[22] D. Schröder, S. Shaik, and H. Schwarz, "Two-state reactivity as a new concept in organometallic chemistry," Accounts of Chemical Research, vol. 33, no. 3, pp. 139-145, 2000.

[23] S. H. Vosko, L. Wilk, and M. Nusair, "Accurate spin-dependent electron liquid correlation energies for local spin density calculations: a critical analysis," Canadian Journal of Physics, vol. 58, no. 8, pp. 1200-1211, 1980.

[24] P. J. Stephens and F. J. Devlin, "Ab initio calculation of vibrational absorption and circular dichroism spectra using density functional force fields: a comparison of local, nonlocal, and hybrid density functionals," Journal of Physical Chemistry, vol. 99, 1995.

[25] R. Colle and O. Salvetti, "Generalization of the Colle-Salvetti correlation energy method to a many-determinant wave function," The Journal of Chemical Physics, vol. 93, no. 1, pp. 534-544, 1990.

[26] W. Hehre, S. Ohlinger, P. Klunzinger, B. Deppmeier, A. Driessen, and J. Johnson, "Spartan'16 tutorial and user's guide,” 2017, https://dasher.wustl.edu/chem430/software/ spartan/spartan-manual-16.pdf.

[27] A. D. Becke, "A new mixing of Hartree-Fock and local density-functional theories," The Journal of Chemical Physics, vol. 98, no. 2, pp. 1372-1377, 1993.

[28] M. Clark, R. D. Cramer, and N. Van Opdenbosch, "Validation of the general purpose tripos 5.2 force field," Journal of Computational Chemistry, vol. 10, no. 8, pp. 982-1012, 1989. 